\title{
Turkish Reduplicative Adjectives and Adverbs
}

\author{
Neşe Demir ${ }^{*}$
}

\begin{abstract}
This research examines a partial (emphatic) reduplication process in Turkish that forms intensified adjectives/adverbs with one of four linkers $m, p, r$, and $s$ (e.g., bem.bejaz, ip.iri). This study goes beyond earlier works by investigating the responses of native Turkish speakers to intensifying nonce words without limiting them about the choice of linkers. The results indicate although this reduplication process is influenced by phonology, the selection of linkers is lexically determined in existing Turkish adjectives/adverbs. With nonce words, native speakers appear to adopt secondary strategies that include using a linker copied from the base, omitting a linker, and dissimilation of the linker and the initial consonant of a $\mathrm{C}$-initial base.
\end{abstract}

Keywords. Turkish; partial reduplication; intensification; lexicalization; production task

1. Introduction. Turkish is an agglutinating language in which derivations and inflections are predominantly formed by suffixing processes; however, it has an interesting prefixation phenomenon when it comes to adjectives and adverbs. Intensified adjectives and intensified adverbs are formed through a morpho-semantic process called 'emphatic partial reduplication,' where 'emphatic' form generally refers to 'optimally perfect of quality' (Demircan 1987).

The formation of emphatic partial reduplication is realized by creating a reduplicant which is a copy of the first syllable $((\mathrm{C}) \mathrm{V})$ of the base, which is then prefixed to the base, and closed with $[\mathrm{p}],[\mathrm{s}],[\mathrm{m}]$, or $[\mathrm{r}]^{1}$ (Kornfilt 1997). With all instances of partial reduplication with $\mathrm{V}$-initial bases, [p] is the linker observed. With $\mathrm{C}$-initial stems, all four of the linker consonants are observed, but [p] is the most common and [r] the least common (i.e., out of 89 attested partially reduplicated C-initial Turkish words, 48 are [p] and 5 are [r]). Partially reduplicated words reported for Standard Turkish are exemplified in Table 1, and linkers are in bold.

\begin{tabular}{|c|c|c|c|}
\hline \multicolumn{2}{|c|}{$C$-initial stems } & \multicolumn{2}{|c|}{ V-initial stems } \\
\hline $\begin{array}{l}\text { bejaz 'white' } \\
\text { t firkin 'ugly' } \\
\text { t fabuk 'fast' } \\
\text { katu 'hard' }\end{array}$ & 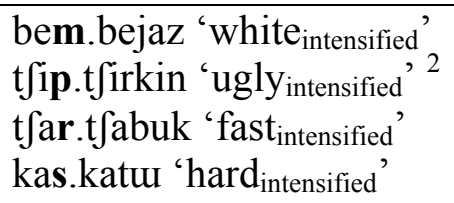 & $\begin{array}{l}\text { adzu 'bitter' } \\
\text { uslak 'wet' } \\
\text { uzun 'long' }\end{array}$ & $\begin{array}{l}\text { ap.adzu 'bitter } \text { intensified' } \text { ' } \\
\text { up.uslak 'wet } \\
\text { up.uztensified' } \\
\text { up.un 'long } \text { intensified }^{\text {' }}\end{array}$ \\
\hline
\end{tabular}

Table 1: Examples for Turkish partial reduplication ${ }^{3}$

\footnotetext{
* I am grateful to Christopher Green, Jaklin Kornfilt, Emma Ticio Quesada, Sharon Rose, and Eric Baković for their helpful comments and suggestions on the earlier drafts of this paper. I also thank to the members of The Phon Company at UCSD, and the attendees at the Tu+3 Workshop and LSA 2018 Annual Meeting for feedback and discussion. All errors are mine. Author: Neşe Demir, University of California, San Diego (ndemir@ucsd.edu).

${ }^{1}$ The standard Turkish $r$ is an alveolar tap [ $\mathrm{c}$ ] (Göksel and Kerslake 2005, Kornfilt 1997). In all of the transcriptions here, I use [r] to remain consistent with the orthography and phonetic transcriptions.

${ }^{2}$ Some partially reduplicated forms with [p] may appear with an epenthetic vowel after [p] and before the base. For

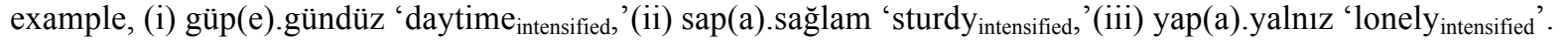

Such cases are optional and rare so they are ignored in this study.

${ }^{3}$ The dot in the reduplicated forms shows the reduplication boundary, not the syllable boundary.
} 
The formation of Turkish partial reduplication appears to be fixed with V-initial bases; however, the problem remains as to the distribution of the linker with $\mathrm{C}$-initial bases. With C-initial bases, what determines the choice of the linker? Can the linker be predicted phonologically? Or, are linkers not predictable and entirely lexicalized? Can native speakers extend their knowledge of choice of linker consonant to nonce words; if yes, how much analogy do they use when they do so? The rest of this paper is an attempt to answer these questions.

2. Previous Research. Earlier studies of Turkish emphatic reduplication generally fall into three basic approaches: Lexical analysis, phonological analysis, and a mixture of lexical and phonological analysis. A lexical approach to partial reduplication advocates that the choice of linker is lexically determined and therefore cannot be predicted based on any property of the base (Foster 1969, Dobrovolsky 1987, Lewis 2000). Phonological analyses suggest the choice of linker is based on certain phonological constraints (Demircan 1987, Taneri 1990, Kelepir 2001). Mixed analyses argue that the linker $[\mathrm{r}]$ is lexicalized but the choice of linkers $[\mathrm{p}, \mathrm{s}, \mathrm{m}]$ is determined by phonological constraints (Wedel 1999, Abbasi and Moradkhani 2012).

One of the well-cited phonological analyses on Turkish partial reduplication is Kelepir's (2001) Optimality Theoretical analysis, where she suggests seven markedness constraints to account for the attested partially reduplicated forms in Turkish. The constraints suggested by Kelepir penalize segments which share similar features in place (labial, coronal) and/or manner (continuant, strident, sonorant). These constraints are listed in (1).

$$
\begin{array}{ll}
* \text { Repeat [strident]: } & \begin{array}{l}
\text { Don't have the strident linker [s] if there is a strident in the whole } \\
\text { base. }
\end{array} \\
* \text {-pb-: } & \begin{array}{l}
\text { Don't have the linker }[\mathrm{p}] \text { with }[\mathrm{b}]-\text { initial bases. } \\
\text { Don't have a [labial] }[\text { labial] sequence at the reduplication } \\
\text { boundary. }
\end{array} \\
* \alpha \mathrm{CONT} \sim \alpha \mathrm{CONT}: & \begin{array}{l}
\text { Don't have a linker that corresponds with the } 2^{\text {nd }} \text { consonant of the } \\
\text { base in terms of continuancy. } \\
\text { Don't have the coronal linker }[\mathrm{r}] \text { and }[\mathrm{s}] \text { if the } 2^{\text {nd }} \text { consonant of the } \\
\text { base is coronal. }
\end{array} \\
* \mathrm{COR} \sim \mathrm{COR} & \begin{array}{l}
\text { Don't have the labial linker }[\mathrm{p}] \text { and }[\mathrm{m}] \text { if the } 2^{\text {nd }} \text { consonant of the } \\
\text { base is labial. } \\
\text { Don't have a linker that corresponds with the } 2^{\text {nd }} \text { consonant of the } \\
\text { base in terms of sonority. }
\end{array}
\end{array}
$$

The ranking of the constraints introduced in (1) is: *Repeat [strident], *-pb- >> *lab-lab (adjacent) $>>* \alpha \mathrm{CONT} \sim \alpha \mathrm{CONT}>>* \mathrm{COR} \sim \mathrm{COR},{ }^{*} \mathrm{LAB} \sim \mathrm{LAB}>>* \alpha \mathrm{SON} \sim \alpha \mathrm{SON}$.

According to this ranking, the tableau in Table 2 provides an example; the derivation of the reduplicated form of bejaz, where RED represents the reduplicant which includes an epenthesized linking consonant [p], [s], or [m]. 


\begin{tabular}{|ll||c|c|}
\hline & /RED+bejaz/ & $*$ Repeat [strident] & $*$-pb- \\
\hline \hline a) & bep.bejaz & & $* !$ \\
\hline b) & bes.bejaz & $* !$ & \\
\hline c) & bem.bejaz & & \\
\hline
\end{tabular}

Table 2: Derivation of bejaz

In Table 2, the optimal candidate is bem.bejaz because bep.bejaz violates *-pb- due to the adjacent -pb- sequence at the reduplication boundary, and bes.bejaz violates *Repeat [strident] since there is another strident (i.e., [z]) in the base. The fourth potential candidate [r] is not included in this tableau because Kelepir considers the linker [r] as an escape hatch, which is considered as a candidate when constraints like *Repeat [strident], *-pb-, and *LAB LAB cannot be satisfied by all the other candidates. Table 3 provides an example derivation where the candidate with $[\mathrm{r}]$ is included in the tableau.

\begin{tabular}{|ll||c|c|}
\hline & /RED +temiz/ & $*$ Repeat [strident] & $*$ LAB LAB \\
\hline \hline a) & tep.temiz & & $* !$ \\
\hline b) & tes.temiz & $* !$ & \\
\hline c) & tem.temiz & & $* !$ \\
\hline d) & ter.temiz & & \\
\hline
\end{tabular}

Table 3: Derivation of temiz

Nevertheless, $[\mathrm{r}]$ being an escape hatch is against the richness of the base (ROTB) (Prince and Smolensky 1993, Smolensky 1996), which asserts there are no language-particular restrictions on the input and all surface structures must be derived from the interaction between markedness and faithfulness constraints. If we assume ROTB, and if [r] is specified in the input, the optimal candidate for reduplicated kodza would be kor.kodza instead of the attested form kos.kodza as shown in Table 4. Three constraints (*-pb-, *lab-lab (adjacent), and *LAB LAB) are omitted from the tableau below because they do not apply to any of the candidates.

\begin{tabular}{|c|c|c|c|c|}
\hline /RED+kodza/ & *Repeat [strident] & ${ }^{*} \alpha \mathrm{CONT} \sim \alpha \mathrm{CONT}$ & $* \mathrm{COR} \sim \mathrm{COR}$ & $* \alpha \mathrm{SON} \sim \alpha \mathrm{SON}$ \\
\hline a) kop.kodza & & $* !$ & & $*$ \\
\hline b) $: 2$ kos.kodza & $* !$ & & $*$ & $*$ \\
\hline c) kom.kodza & & $* !^{4}$ & & \\
\hline d) $\$$ kor.kodza & & & $* !$ & \\
\hline
\end{tabular}

Table 4: Derivation of kodza

Another problem with Table 4 is that even if the candidate with [r] is not included in the tableau, Kelepir's constraints cannot capture the attested reduplicated form kos.kodza because it violates the highest ranked consontraint * Repeat [strident]. Instead, these constraints would choose kom.kodza as the optimal candidate. In fact, Kelepir's analysis falls short as it cannot account for $24(27 \%)$ words out of 89 C-initial attested reduplicated forms that exist in Turkish.

Since the qualities of the vowels appear not to have an influence on the selection of the linker in Turkish partial reduplication, Kelepir's analysis cannot account for the bases with the same

\footnotetext{
${ }^{4}$ Nasals and affricates are both treated as [-continuant] in this paper.
} 
consonant pattern but with a different linker. For instance, kas.katu 'hard intensified' and $k ø p . k ø t y$ 'badintensified' have the same $k-t$ - consonant pattern in their bases, but one is reduplicated with [s] and the other with [p].

Some authors like Taneri (1990) and Demircan (1987) attempted to test native speakers' knowledge of Turkish partial reduplication. Taneri (1990) elicited the intuitions of 32 native speakers regarding the reduplicated forms of about 300 Turkish adjectives and adverbs. Taneri's study revealed that there was a hierarchy in the choice of the linker: $[\mathrm{p}]>[\mathrm{s}]>[\mathrm{m}]>[\mathrm{r}]$ based on frequency of occurrence. The study also reveals that partial reduplication in Turkish is a dissimilative process of a linker with respect to the consonants in the base (primarily the first two consonants). According to Taneri, (i) the linking consonant [p] appears when the consonants in the base are [-labial], (ii) when [s] is found as a linker, the initial consonant of the base is never a strident, (iii) when the linker is [m], the consonants in the base are [-nasal], and (iv) [r] is rare as a linker and used when certain adjectives/adverbs do not meet the structural descriptions formulated in (i-iii). Nevertheless, Taneri's descriptions do not always work; for instance, linker [p] is used in sap.sa:lam 'sturdy intensified,' zap.zajuff 'thin intensified,' and sip.sivri 'sharpintensified' where each base contains a [+labial] sound.

Demircan's (1987) study consisted of two experiments conducted with 100 university students. One of the experiments required the participants to circle one intensified form of a given adjective (that has an attested reduplicated form) among four possibilities; for instance, sijah 'black:' sim.sijah, sip.sijah, sir.sijah, sis.sijah. The second experiment had the same format except that it only included non-existent but possible adjectives in Turkish; for example, tupa: tum.tupa, tup.tupa, tur.tupa, tus.tupa.

Demircan's study concludes Turkish partial reduplication consists of some avoidance strategies: (i) avoiding the identity between the linker and any consonant that appears in the base (e.g., *sam.sa:lam), (ii) avoiding the similarity between the linker and the $2^{\text {nd }} \mathrm{C}$ of a C-initial base (e.g., *sem.sefil, where [m] and [f] are both labial), and (iii) avoiding homorganic sequences like -pb-,-stf- at the morpheme boundary (e.g., *tfas.tfabuk). Preference order of linkers according to Demircan is the same as what Taneri found; $[\mathrm{p}]>[\mathrm{s}]>[\mathrm{m}]>[\mathrm{r}]$, and also matches that of the phonological analysis of Kelepir.

Although such nonce word studies give the general picture and capture most of the attested reduplicated forms, these were forced-choice experiments. The rest of this paper will introduce two experiments where native speakers were not limited with four options as a linker.

3. Experiment I. The purpose of this experiment is to observe what happens if native speakers are given more flexibility when choosing linkers for nonce words. Do they always use the attested linkers $[\mathrm{p}, \mathrm{s}, \mathrm{m}, \mathrm{r}]$ ? Do they adopt other strategies when they partially reduplicate words, and what kind of conclusions can we draw from this experiment about the attested reduplicated forms in Turkish? The prediction regarding real words and V-initial nonce words is full accuracy since $\mathrm{V}$-initial words are always reduplicated with [p]. As for C-initial bases, only the attested linkers $([\mathrm{p}, \mathrm{s}, \mathrm{m}, \mathrm{r}])$ are predicted to be used. High accuracy with real words and variation with nonce words are predicted. It is also expected based on previous studies (Demircan 1987, Taneri 1990) that there would be resistance to identity/high similarity between the linker and the sounds in the base, and these restrictions are worse when the sounds are adjacent. For instance, no linker $[\mathrm{p}]$ is predicted if the base starts with a labial like [p] or [b], no [s] adjacent to [s, $\mathrm{z}, \int$, $\mathrm{t} f]$, and no [m] adjacent to [m]. This experiment might also reveal other strategies used by native 
speakers.

\subsection{METHOD}

Participants. The subjects of this study were 125 (44M, 78F, 3 unspecified) self-identified literate native speakers of Turkish, who are 18 years old or older. Participants were recruited voluntarily from various geographical areas in Turkey and the US. Participants were not selected based on any particular factor like age, gender, race, ethnic origin, religion, and social or economic profile. However, the subjects were expected to have basic computer skills in order to be able to complete an online survey independently.

Procedure. Data was collected through a questionnaire released in an online platform. Subjects were given 10 actual Turkish adjectives/adverbs and asked to reduplicate (intensify) them. The remainder of the survey provided the participants with 34 nonce Turkish words. At the beginning of each section of the questionnaire, participants were supplied with examples (i.e. yemyeşil, upuzun, kupkuru, tertemiz, büsbütün), which guided them to intensify the words through partial reduplication processes but not other reduplication types in Turkish (e.g., using an adverb to intensify the meaning, total reduplication, etc.). Participants were not told which linking consonants they should choose so they had the liberty of choosing any consonant in the Turkish alphabet. This flexibility for the participants was a significant methodological choice adopted for this experiment and is one characteristic that distinguishes this study from the approaches taken by Demircan (1987) and Taneri (1990). Demographic information about sex, dialect, and education was also collected in this survey.

Selection/Formation of Words. The existing adjectives/adverbs and the nonce words that were presented in the survey were selected based on certain criteria. Of the existing 10 Turkish words, two are $\mathrm{V}$-initial and 8 are $\mathrm{C}$-initial. These words vary in syllable count and the linker they take in their reduplicated forms. The nonce words in this experiment ( $8 \mathrm{~V}$-initial and $26 \mathrm{C}$-initial) vary in terms of syllable count, first consonant of the base, and the consonant following the first vowel. These nonce words were not assigned any meaning but participants were asked to imagine that they were real Turkish adjectives or adverbs and use their native judgments to intensify these words. Each ${ }^{5}$ nonce word coined for the experiment fits Turkish vowel harmony rules so that they would sound natural. In addition to these principles, the consonant patterns in two nonce words were purposefully designed to be the same as some existent words: nonce sifel versus sefil 'miserable,' and nonce sayth versus siyah 'black.' The words used in this experiment are summarized in Table 5.

\footnotetext{
${ }^{5}$ Ahur is an exception. Although it does not fit the vowel harmony, it is not trivial in terms of the results of this experiment because ahur is V-initial and the only linker predicted for the reduplicated form of ahur is [p]. In addition, there are native Turkish words with an $a-u$ sequence such as avuç 'palm,' kabuk 'shell,' çamur 'mud,' and kavun 'melon,' so ahur should not sound odd to native Turkish speakers.
} 


\begin{tabular}{|c|c|c|c|c|}
\hline \multirow[t]{2}{*}{ Turkish words } & \multicolumn{4}{|c|}{ Nonce words } \\
\hline & $V$-initial & & $C$-initial & \\
\hline \multirow{10}{*}{$\begin{array}{l}\text { ansızın /ansuzun/ } \\
\text { iri /iri/ } \\
\text { belli /belli/ } \\
\text { boş /bof/ } \\
\text { perişan /perifan/ } \\
\text { sefil /sefil/ } \\
\text { sicak /sudzak/ } \\
\text { siyah /sijah/ } \\
\text { tatlı /tatlu/ } \\
\text { yuvarlak /juvarlak/ }\end{array}$} & \multirow{10}{*}{$\begin{array}{l}\text { ahur /ahur/ } \\
\text { esik /esik/ } \\
\text { irağ1 /urau// } \\
\text { ivir /ivir/ } \\
\text { oracı /oradzu/ } \\
\text { ötük /øtyk/ } \\
\text { uyuk /ujuk/ } \\
\text { üsül /ysyl/ }\end{array}$} & labial-initial & strident-initial & other C-initials \\
\hline & & bakaç /bakatj/ & çarmık /tfarmuk/ & dizit /dizit/ \\
\hline & & bayaş /bajaj/ & sayıh /sajuh/ & düvel /dyvel/ \\
\hline & & berili /berili/ & savuk /savuk/ & göcek /gødzek/ \\
\hline & & betil /betil/ & sifel /sifel/ & güler /gyler/ \\
\hline & & bon /bon/ & sitilik / sitilik/ & hombul/hombul/ \\
\hline & & meşik /mefik/ & şipen / Jipen/ & kadık /kaduk/ \\
\hline & & parak /parak/ & zugan & las /las/ \\
\hline & & & & \\
\hline & & $\begin{array}{l}\text { pisli /pisli/ } \\
\text { pörüşük /pøry } y \text { yk/ }\end{array}$ & & \\
\hline
\end{tabular}

Table 5: The words used in Experiment I

\subsection{RESULTS AND DisCUSSION}

Turkish Words. This section presents the results of the data represented in Table 5. Figure 1 illustrates the distribution of the responses. White bars are the expected or predicted responses based on attested forms in Turkish. The black bars represent other responses, which may be a different linker from the set [p, s, m, r] or another consonant. As it was predicted, it is apparent from Figure 1 that most native speakers know the reduplicated forms of these 10 Turkish words, but their choice of linkers is not consistent for every word.

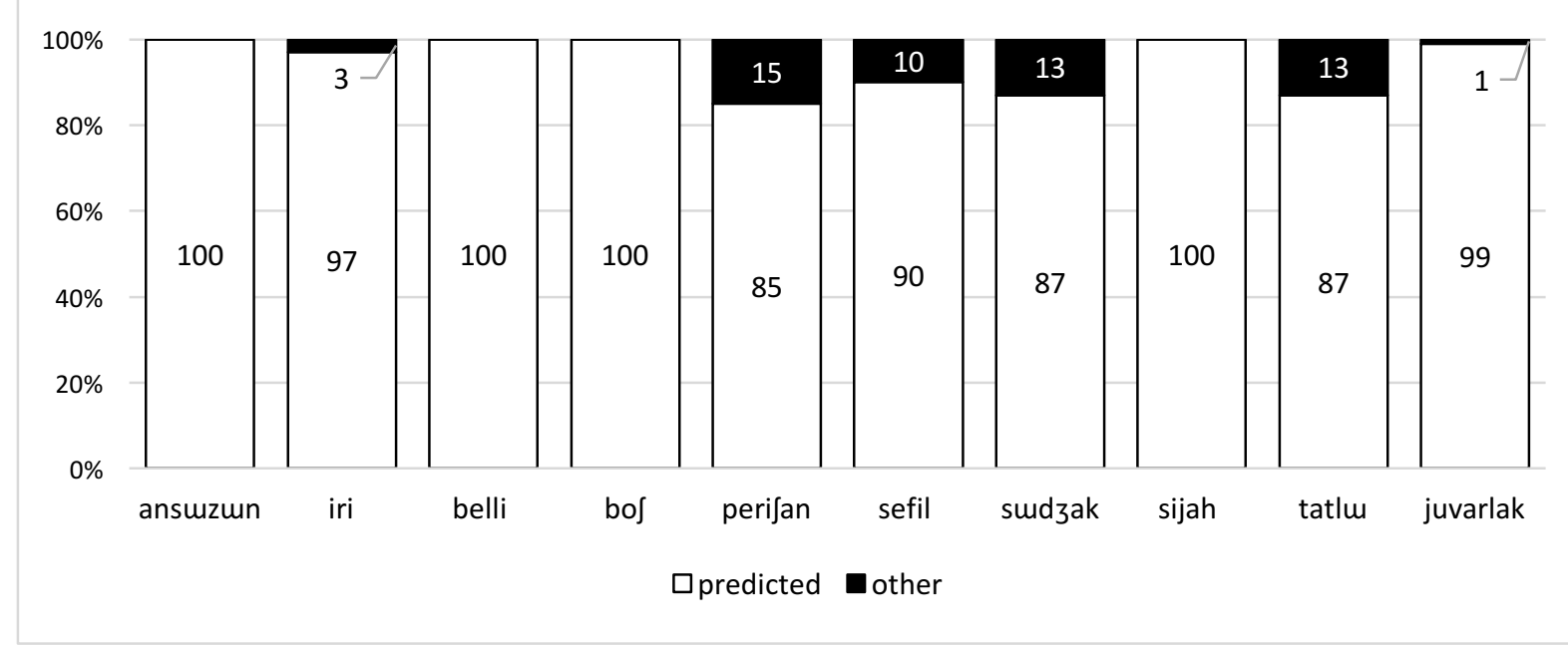

Figure 1: Turkish words

The frequencies of the responses that have some sort of variation are given in Table 6. Choice of other variant is usually one of the other three attested linkers (97\%), which can be seen in the rightmost column of Table 6 . The alternate forms used by participants seem to follow previously noted constraints against adjacent identical consonants. In other words, no [p] is chosen with a [p]-initial base and no [s] appears before an [s]-initial base. Moreover, there seems to be a priority order: $[\mathrm{p}]$ is always preferred to [s] unless the base starts with a labial, and [s] is preferred to $[\mathrm{m}]$. 


\begin{tabular}{lll}
\hline base & predicted reduplicated form & other variants used by participants \\
\hline perifan & per.perifan (103) & $\mathrm{s}(16), \mathrm{m}(2)$ \\
sefil & ser.sefil $(112)$ & $\mathrm{p}(10), 1(1)$ \\
sudzak & sum.sudzak (106) & $\mathrm{p} \mathrm{(16)}$ \\
tatlu & tap.tatlu (103) & $\mathrm{s}(12), \mathrm{m}(2), \mathrm{b}(1)$ \\
iri & ip.iri (119) & $\mathrm{s}(4)$ \\
yuvarlak & yus.yuvarlak (123) & $\mathrm{p} \mathrm{(1)}$ \\
\hline
\end{tabular}

Table 6: Frequencies of the words in Figure 1 that have other variants

V-Initial Nonce Words. As for the V-initial nonce words, a majority of the participants selected the predicted reduplicated form [p] accurately, but there is a greater variety in terms of participants' selections of linkers in Figure 2 compared to the results of V-initial Turkish words in Figure 1. In fact, all of the $\mathrm{V}$-initial nonce words in Figure 2 have variation to some extent, and this is an unpredicted result since all $\mathrm{V}$-initial real word bases are reduplicated with [p].

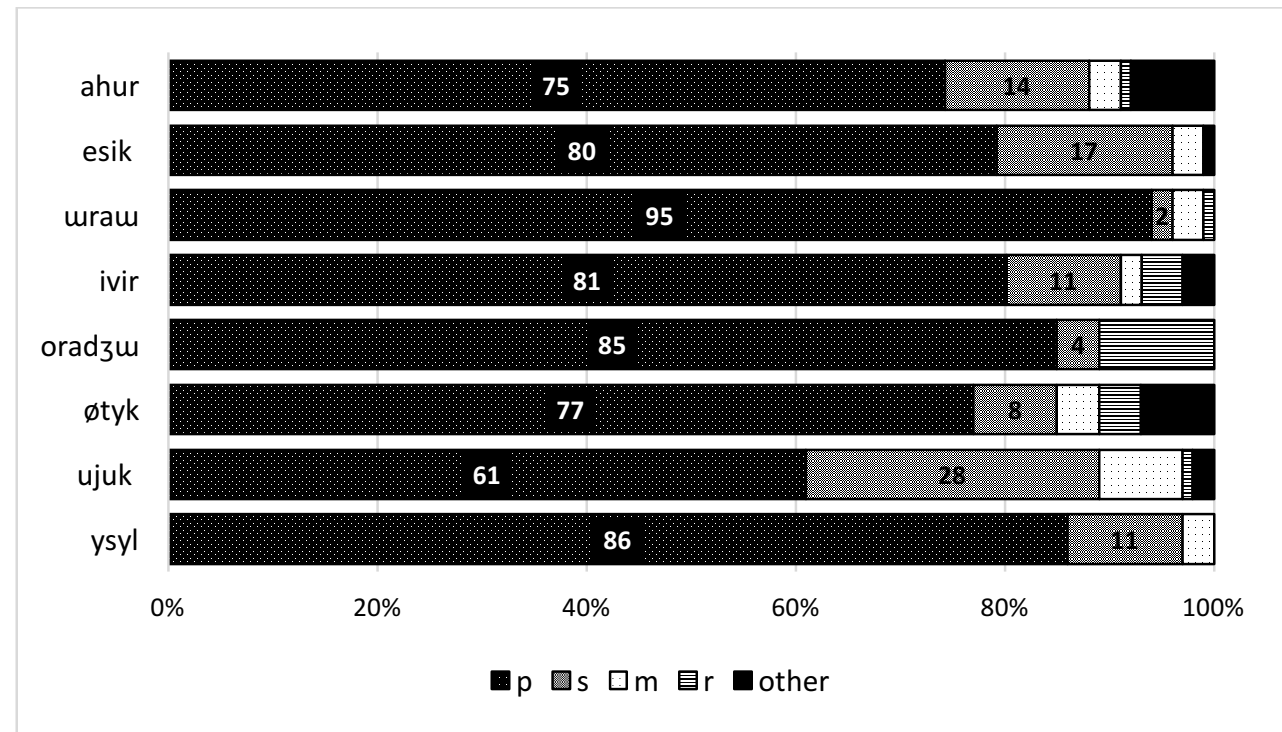

Figure 2: V-initial nonce words

Table 7 shows the frequencies of linkers preferred by native speakers. When [p] is not selected, 22 novel linkers ([h, n, k, v, t, y]) appear in total. 20 of these appear to be copied from the base correspondent of the linker: ah.ahur (7), iv.ivir (3), øt.øtyk (8), uj.ujuk (2). One of the unattested linkers is identical to the last consonant of the base (ek.esik), and the other cannot be explained an.ahur (1). If copying a consonant from the base and using it as a linker is a strategic pattern, it could be that the linkers were also chosen in this manner for forms that have [s] or [r] as the second consonant: es.esik (19), ys.ysyl (13), and or.oradzu (12). Table 7 also indicates that when predicted $[\mathrm{p}]$ is not selected, participants choose $[\mathrm{s}]$ so the general strategy appears to be $[\mathrm{s}]>$ $[\mathrm{m}]>[\mathrm{r}]$. 


\begin{tabular}{|c|c|c|}
\hline base & predicted & other variants used by participants \\
\hline ahur & ap.ahur (79) & s (15), h (7), m (3), r (1), n (1) \\
\hline esik & ep.esik (90) & $\mathrm{s}(19), \mathrm{m}(3), \mathrm{k}(1)$ \\
\hline urau & up.urau (114) & $\mathrm{s}(2), \mathrm{m}(1), \mathrm{r}(1)$ \\
\hline ivir & ip.ivir (92) & $\mathrm{s}(13), \mathrm{r}(4), \mathrm{v}(3), \mathrm{m}(2)$ \\
\hline oradzu & op.oradzu (91) & $\mathrm{r}(12), \mathrm{s}(4)$ \\
\hline øtyk & øp.øtyk (87) & $\mathrm{s}(9), \mathrm{t}(8), \mathrm{m}(5), \mathrm{r}(4)$ \\
\hline ujuk & up.ujuk (70) & $\mathrm{s}(32), \mathrm{m}(9), \mathrm{y}(2), \mathrm{r}(1)$ \\
\hline ysyl & yp.ysyl (102) & $\mathrm{s}(13), \mathrm{m}(3)$ \\
\hline
\end{tabular}

Table 7: Frequencies of the words in Figure 2 that have other variants

C-Initial Nonce Words. As illustrated in Table 5 in Section 3.1, a total of 26 C-initial nonce words were presented to native Turkish speakers in Experiment I. The distribution of linkers is examined based on the nature of the initial consonant of the base: Figure 3 demonstrates stridentinitial bases, Figure 4 illustrates labial-initial bases, and Figure 5 shows other C-initial bases that include dorsal or coronal-initials. The last category 'other' in each figure indicates linkers (or strategies) used by participants other than [p, s, m, r]. To clarify, it refers to linkers that appear to be copied from the base, a linker that does not appear in the base, and an omitted linking consonant (e.g., fi.fipen, me.mefik, di.dizit).

It is clear from Figure 3 that bases starting with a strident strongly disfavor [s] as linker and the general preference is [p]. With bases starting with [s], linker [s] is never selected, and with bases starting with other stridents like $\left[\mathrm{t} \int, \int, \mathrm{z}\right]$, linker $[\mathrm{s}]$ is rarely selected. However, it seems like linker [s] is more acceptable with a [t [] -initial base compared to $\left[\int\right]$ or $[\mathrm{z}]$-initial bases. Another observation is the large number of [r] responses with savuk. The reason for this might be that [s] is strongly disfavored since the base starts with [s], and the selection of labial linkers [p] and [m] is relatively smaller since the [+labial] feature of the second base consonant [v] corresponds to the [+labial] feature of [p] and [m]. Nevertheless, in sifel, which is another [s]-initial base, the second base consonant is [f], which is also labial, and yet there is no strong preference for [r]. In other words, savuk and sifel are quite similar but linker [r] is not as frequently preferred in sifel as it is in savuk.

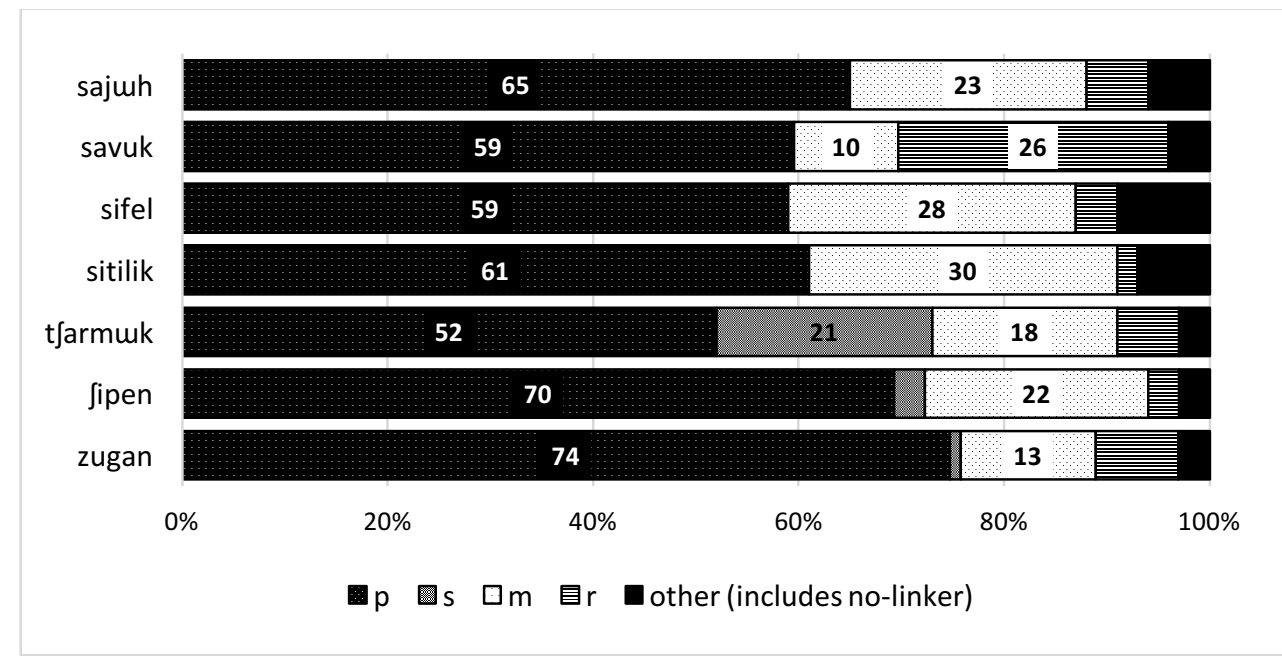

Figure 3: Strident-initial nonce words 
According to Figure 4, bases starting with a labial disfavor linker [p], and the general preference is [s]. Compared to the other [b]-initial words in Figure 4, [s] is less common in bakat fand bajaf; instead, the number of [m] increases. This might be because bakatf and bajaf have a strident in their bases. It could also be that homorganic nasal-voiced stop sequences are generally favored cross-linguistically (Pater 2004), and the sequence [mb] is acceptable in Turkish. In the case of pisli, [p] is not selected because the base starts with [p], and it seems like [s] is not common either because the second base consonant is [s], so the rate of selection of the third most common linker $[\mathrm{m}]$ increases. Two examples where [r] selection increases are pøry/yk and pevin, both of which are [p]-initial and therefore [p] is not selected. In either case, [s] and [r] are almost equally common. With pøry/yk, the [r] may be copied from the base. As for pevin, the second most common linker [s] would be predicted since there is no strident in the base. The increase in the selection of [r] is similar to the preferences for savuk in Figure 3. The increase in [r] responses may be due to the fact that there are two labials in the word, which disfavors [m] as a choice, thereby increasing the rate of $[r]$.

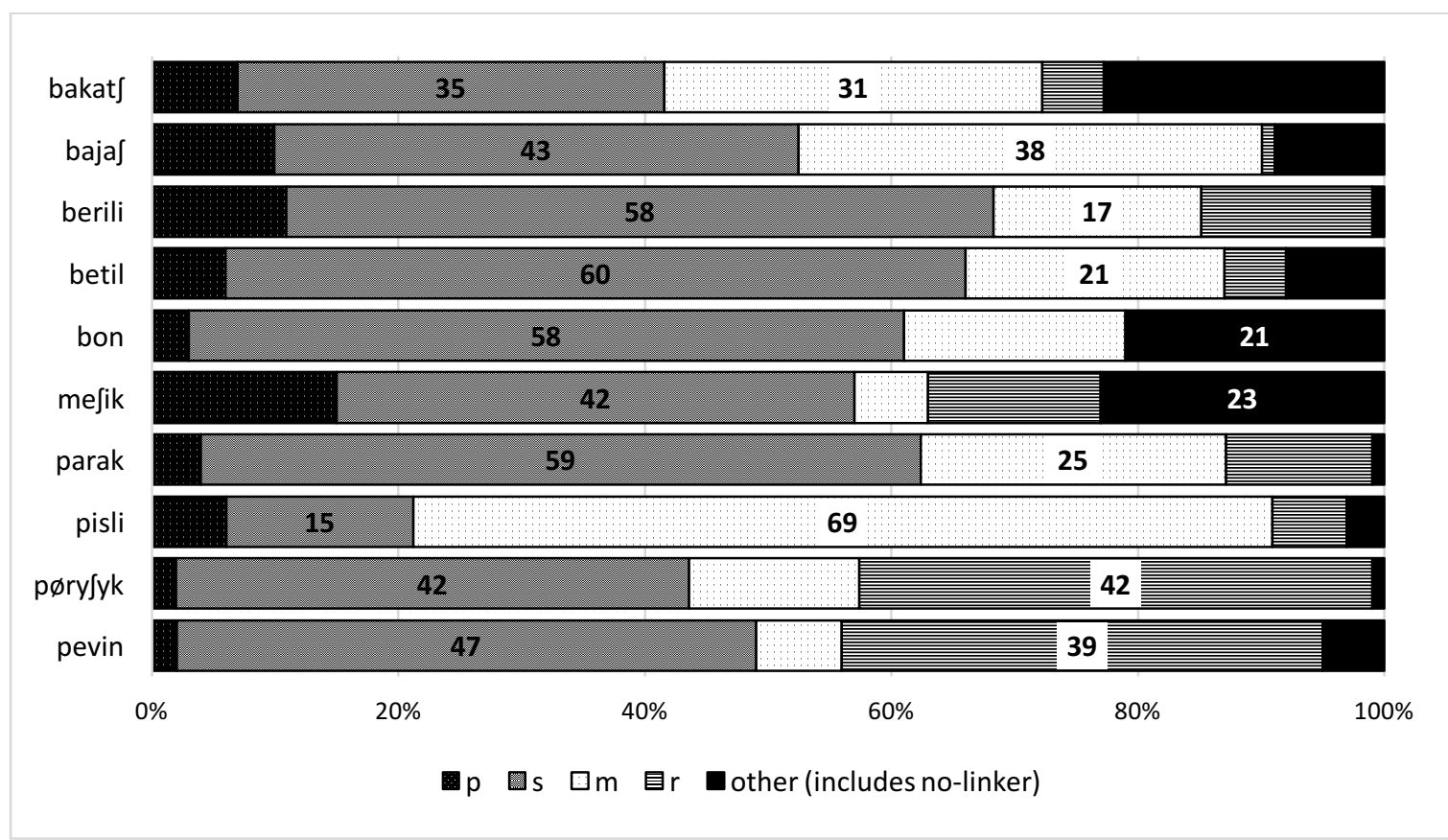

Figure 4: Labial-initial nonce words

Finally, Figure 5 represents the results of other C-initial nonce words. The general preference order of $[\mathrm{p}]>[\mathrm{s}]>[\mathrm{m}]>[\mathrm{r}]$ is observed in this figure as well. With dizit and las, [s] is less preferable because the second base consonant is a strident. The reason why [p] is less preferred than [s] in hombul could be because the base has two labial segments (i.e., $m b$ ) after the first consonant. What is surprising in Figure 5 is the distribution of linkers in terik. Given the general preference order and that terik does not contain a labial or a strident, [p] would be the best prediction. However, native speakers seem to like the least common linker [r] with terik, which seems to be copied from the base. There appears to be a decrease in the choice of [p] if the first consonant is voiceless, particularly a voiceless stop. So, the combination of that with [r] as a possible copy of the base boosts the number of $[\mathrm{r}]$ responses. 


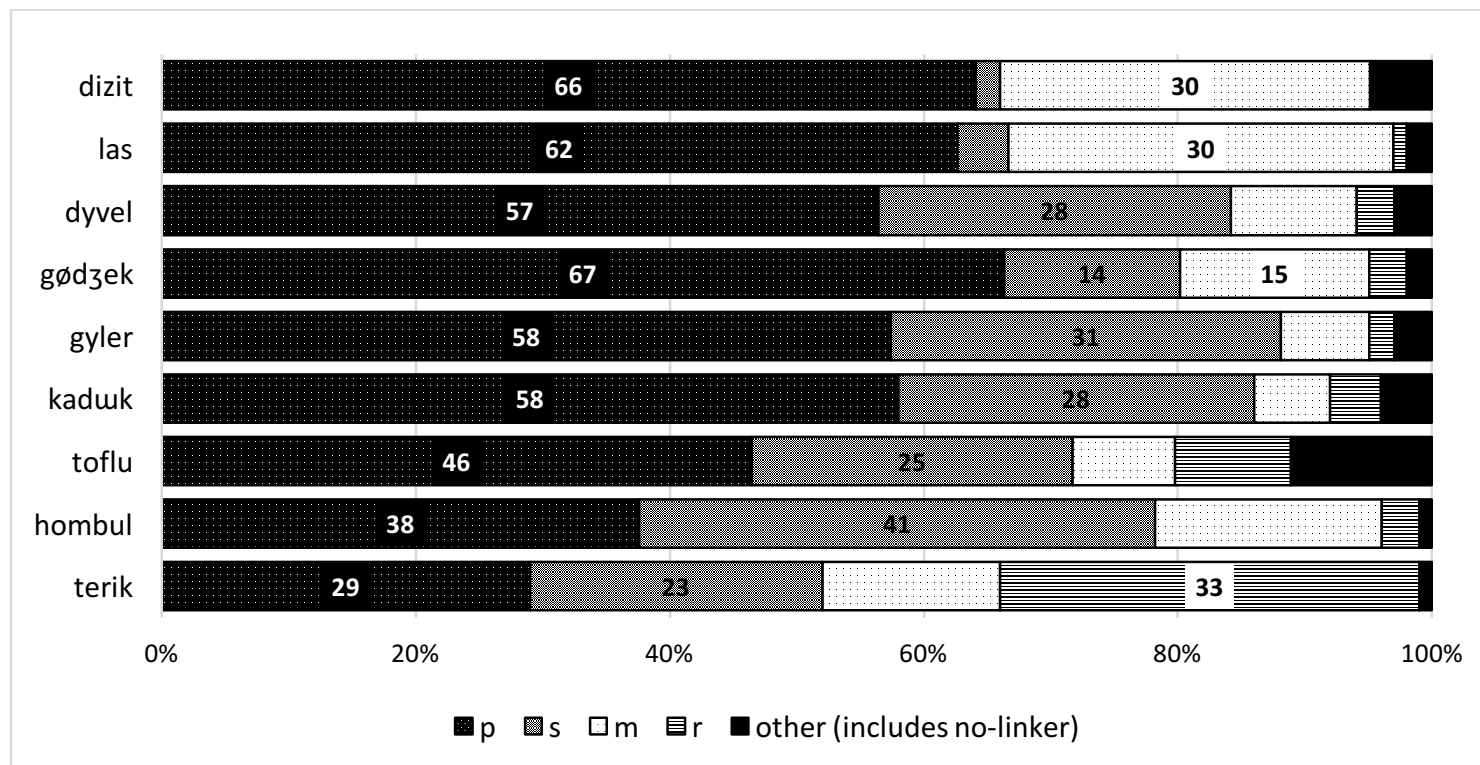

Figure 5: Other C-initial nonce words

In summary, with V-initial nonce words, native speakers mostly choose [p], which appears to be the most common linker. Even though all V-initial words in Turkish take [p] as a linker, in nonce words, the speakers do not select [p] all the time. This suggests that some speakers may be relying more on phonological information in the nonce word task, which would be suppressed by lexical choice in real Turkish words. With C-initial words, there is some effect of phonology similar to the findings of earlier research (Demircan 1987, Taneri 1990). When native speakers are not relying on linkers connected to specific lexical items, they tend to use attested linkers [p, $\mathrm{s}, \mathrm{m}, \mathrm{r}]$. However, they also use secondary strategies like apparent copying mostly the second consonant of the base which would match the position of the second consonant of the prefix, or using a linker which is not a copy from the base or not from the set of [p, s, m, r], or omitting a linker between the reduplicant and the base. Experiment I also provides confirmation for avoidance of similar consonants. If the first base consonant is strident, [p] is the most common linker while $[\mathrm{m}]$ is the next most common one. [s] is completely avoided if the base starts with [s] and is rarely used when the first base consonant is a strident other than [s]. If the first base consonant is labial, native speakers favor linker [s], and when there is a strident elsewhere in the word, then [s] is disfavored over [m]. Finally, if the first base consonant is not $[\mathrm{p}],[\mathrm{s}],[\mathrm{m}]$, or $[\mathrm{r}]$, there seems to be a preference hierarchy of linkers: $[\mathrm{p}]>[\mathrm{s}]>[\mathrm{m}]>[\mathrm{r}]$. In addition to the influence of phonology in Turkish partial reduplication, the higher accuracy with Turkish words in Figure 1 and higher variety of alternative responses with nonce words in Figure 2-5 suggest the possibility that linkers in the attested partially reduplicated constructions in Turkish might be lexicalized but speakers nevertheless have knowledge of phonological factors that contribute to the distribution of the linkers.

Moreover, if the generalization about strident-initial bases and the preference hierarchy is accurate, these factors might explain the difference in linker preference in nonce sifel and

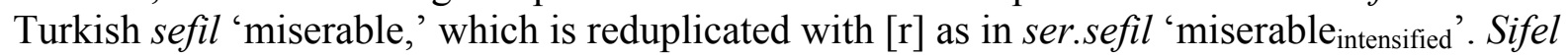
shows a preference for $[\mathrm{p}]$ and not $[\mathrm{r}]$, in accordance with phonological predictions. This demonstrates that speakers may not be relying on close analogy with real words in the selection of the linker but are free to rely more heavily on phonology. The same problem is observed with 
nonce sayth and Turkish sijah 'black,' which is reduplicated with [m] as in sim.sijah 'blackintensified'. Although saymh has the same consonant pattern with sijah, native speakers mostly preferred to reduplicate sayuh with the most common linker [p]. This begs the question of how much analogy native speakers use when they are intensifying adjectives/adverbs through partial reduplication process. This issue is addressed in Experiment II in the next section.

Finally, no noteworthy correlation between the selection of linker in Turkish partial reduplication and the sex/dialect/education level of participants was found in Experiment I. Individual differences were also investigated. A sample group of 30 participants (the first 30 participants in the data) were selected, and the answers of each individual were examined to see if there were any specific pattern a participant used for each item in the experiment. However, it is not the case that an individual consistently ignored the linking consonant or consistently used a linking consonant copied from the base when reduplicating adjectives/adverbs. There are participants who chose a linker among the set of [p, s, m, r], but at the same time omitted a linker between the reduplicant and the base for some items and copied a consonant from the base for some other items. For this reason, the fact that individuals seem not to show specific patterns but adopt a variety of strategies might provide further evidence that the partial reduplication in Turkish involves some lexicalization as suggested earlier (Foster 1969, Dobrovolsky 1987, Wedel 1999, Lewis 2000, Abbasi and Moradkhani 2012).

4. Experiment II. This is a second, follow-up experiment that aims to test the outcome of reduplication with nonce words that have the same consonant patterns as existing Turkish adjectives or adverbs but different vowels. The remainder of this section seeks to determine how much analogy native speakers use with nonce words with the same consonant patterns with Turkish words. Assuming the qualities of vowels in the base do not interfere with the selection of linker, if participants reduplicate nonce words with the same linker used for the attested forms with the same consonant pattern, this will provide evidence that analogy has an important role in the reduplication process. If such nonce words are reduplicated with different linkers than the linker used for the Turkish word with the same consonant pattern, this will support the idea that choice of the linker in partially reduplicated forms in Turkish is likely to be lexicalized but that speakers rely more on phonological knowledge to choose a linker with nonce words.

\subsection{METHOD}

Participants. The number of the participants in this experiment were 38 ( $8 \mathrm{M}$ and $30 \mathrm{~F})$. There was no control over whether the participants of Experiment I also participated in Experiment II. The rest of the criteria for the selection of participants for this experiment are the same as the criteria in Experiment I.

Procedure. In Experiment II, the design of the questionnaire, questions about demographic information, methods of data collection, and recruitment were the same as Experiment I. Twelve nonce words were presented.

Formation of Words. The nonce words for this experiment were coined by the researcher based on the same principles considered for the Experiment I (i.e., V-initial versus C-initial base, syllable count, base-correspondent variety, and vowel harmony). At the same time, each of these 12 words mirrored the consonant pattern of a Turkish adjective/adverb but they differed in vowels. Table 8 compares the nonce words used in Experiment II with real Turkish words, and 
the rightmost column shows the linking consonant used for real words, which is predicted to be the same for the nonce word that has a matching consonant pattern.

\begin{tabular}{|c|c|c|c|c|c|}
\hline & Nonce word & \multicolumn{3}{|c|}{$\begin{array}{l}\text { Turkish word with matching } \\
\text { consonant pattern }\end{array}$} & (predicted) Linker \\
\hline eçek & /etfek/ & açık & /atfunk/ & 'open' & $\mathrm{p}$ \\
\hline öyrü & /øyry/ & ayrı & /ayru/ & 'separate' & $\mathrm{p}$ \\
\hline boyuz & /bojuz/ & beyaz & /bejaz/ & 'white' & $\mathrm{m}$ \\
\hline buş & /buf/ & boş & /bod/ & 'empty' & $\mathrm{m}$ \\
\hline çebik & /tfebik/ & çabuk & /t fabuk/ & 'fast' & $\mathrm{r}$ \\
\hline daran & /daran/ & derin & /derin/ & 'deep' & $\mathrm{p}$ \\
\hline mava & /mava/ & mavi & /mavi/ & 'blue' & S \\
\hline söcek & /sødzek/ & sicak & /surdzak/ & 'hot' & $\mathrm{m}$ \\
\hline tamaz & /tamaz/ & temiz & /temiz/ & 'clean' & $\mathrm{r}$ \\
\hline temim & /temim/ & tamam & /tamaz/ & 'complete' & $\mathrm{s}$ \\
\hline yimre & /jimre/ & yumru & /jumru/ & 'swollen' & $\mathrm{s}$ \\
\hline yongul & /jongul/ & yengil & /jengil/ & 'light' & $\mathrm{p}$ \\
\hline
\end{tabular}

Table 8: Nonce words used for Experiment II, their Turkish equivalences, and predicted linkers

\subsection{RESULTS AND DISCUSSION}

Figure 6 illustrates the results of Experiment II, nonce words with identical consonant patterns to Turkish words. 'Predicted' refers to the predicted linker according to Table 8; '[p, s, m, r] (nonstandard)' refers to the choice of linker from the set of [p, s, m, r] but an unpredicted one; 'copied from the base' is any consonant that is copied from the base and used as a linker; 'no explanation' refers to a linker that does not appear in the base; and finally, 'no linker' is the category which contains reduplicated forms without a linker. Out of these five categories reflected in Figure 6, '[p, s, m, r] (non-standard)' and 'copied from the base' overlap with each other. With bases daran, tamaz, temim, jimre, the linker preference $[\mathrm{r}]$ and $[\mathrm{m}]$ both belong to these two categories. The rightmost four bars in Figure 6 treat [r] with daran and [m] with tamaz, temim, and jimre, as both a base copy and as a non-standard linker. This is indicated with dashes.

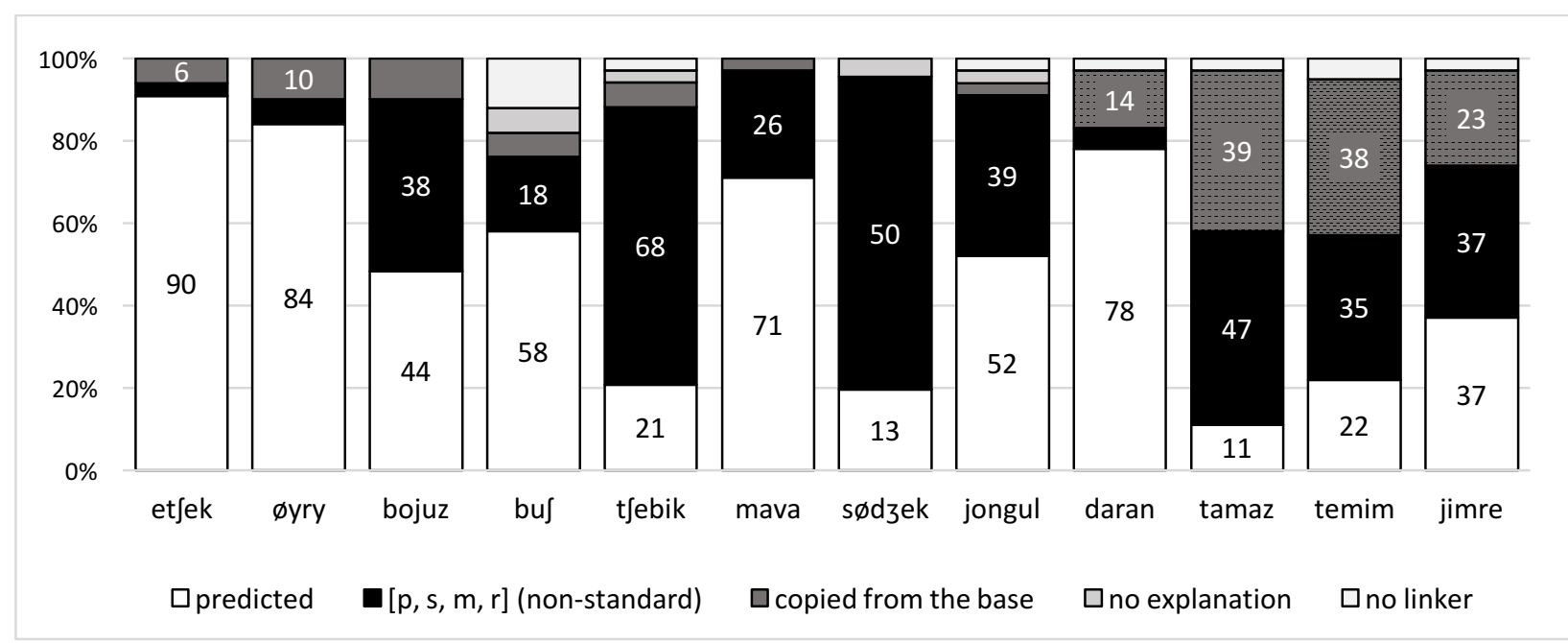

Figure 6: Nonce words with identical consonant patterns to Turkish words 
According to Figure 6, predicted linkers were not routinely selected by native speakers especially with C-initial bases, so it seems like, contrary to what is predicted, native speakers do not use much analogy with nonce words that mirror the consonant pattern of real Turkish words. In fact, the more the consonant pattern of a nonce word is similar to a real word, the less likely native speakers use the predicted form. To clarify, native speaker participants selected a linker other than the predicted for more than half of the C-initial nonce words in Figure 6 (i.e., 6 out of 10 Cinitial nonce words: bojuz, tfebik, sødzek, tamaz, temim, jimre). This suggests the possibility of anti-homophony to the existing forms.

It is not always the case that [p] is chosen when there is strident in the base. For instance, the most commonly preferred linker for tamaz is [m], which corresponds to the second base consonant. The most common linker for temim is [m] contrary to the predicted linker [s]. This is unexpected because there is no [p] or a strident in temim, so one would predict that native speakers would use the most prevalent linker [p] with temim, or if not [p], then [s] would be ideal.

The large variation observed in Experiment II is not reflected in Turkish corpora of real words. Turkish National Corpus (Aksan et al. 2012), TS Corpus (Sezer 2017), and TweetS Corpus (Sezer 2016) were examined for 12 Turkish words shown in Table 10. For each type, four entries were searched (e.g., for temiz, four potential forms were searched: tep.temiz, tes.temiz, tem.temiz, tertemiz). In Turkish National Corpus, out of 3712 tokens, only 1 non-standard variant was found (sup.sudzak). In TS Corpus, out of 12750 tokens, only 5 non-standard variants were found, all being sup.sudzak. Finally, out of 918 tokens in TweetS Corpus, which presumably include more informal instances, only 1 non-standard variant was found (sup.sudzak instead of sum.sudzak). This indicates that sudzak has two variants.

To sum up, this section shows only little variation is found in Turkish corpora, which suggests that the partially reduplicated forms in Turkish are likely to be lexicalized. The fact that there is large variation with the reduplication of nonce words that have identical consonant patterns with Turkish words reveals that native speakers do not use much analogy to determine the linking consonant in partial reduplication.

5. Conclusion. The purpose of this study was to examine the intensifying partial reduplication patterns in modern Turkish with a new experimental approach. Findings of this study indicate that partial reduplication in Turkish is a productive process in that the forms produced generally use one of the four linker consonants [p, s. m, r]. Linkers in existing forms in Turkish are likely to be lexicalized but their distribution is influenced by phonology. One of the strictest avoidance effects observed with nonce words and Turkish words is the avoidance of identity/similarity between the linker and the first base consonant. When native speakers are not drawing directly from the lexicon as in the case of nonce words, they also employ secondary strategies like (i) copying a segment from the base and using it as a linker (e.g., es.esik, boj.bojuz), (ii) a random selection of a linker that is not from the set of $[\mathrm{p}, \mathrm{s}, \mathrm{m}, \mathrm{r}]$ and does not appear in the base (e.g., but.buf, joz.jongul), and (iii) no use of a linker between the reduplicant and the base (e.g., te.temim, ji.jimre).

The experiments in this study have shown that native speakers have good knowledge of the reduplicated forms of existing Turkish words and that they can extend this knowledge to nonce words by producing intensified forms for nonce words by using partial reduplication rules of 
Turkish. However, there is a wide variety of different 'linker' strategies used with the nonce words.

\section{References}

Abbasi, N., \& Moradkhani, E. (2012). Intensified reduplicated adjectives in Azerbaijani Turkish. Social and Behavioral Sciences 70 (2013), 1600-1608.

Aksan, Y., Aksan, M., Koltuksuz, A., Sezer, T. Mersinli, Ü., ...Y1ldı, İ. (2012). In Proceedings of the eighth international conference on language resources and evaluation (LREC 2012). Istanbul.

Demircan, Ö. (1987). Emphatic reduplications in Turkish. In Boeschoten, H. E. \& Verhoeven, L. T. (eds.). Studies in modern Turkish: Proceedings of the third conference on Turkish Linguistics, 24-41. Tilburg: Tilburg University Press.

Dobrovolsky, M. (1987). Why CVC in Turkish reduplication? The Nordic languages and modern linguistics 6: Proceedings of the sixth International Conference of the Nordic and General Linguistics, Helsinki. Helsinki: Helsinki University Press.

Foster, J. F. (1969). On some phonological rules of Turkish (doctoral dissertation). University of Illinois.

Kelepir, M. (2001). To be or not to be faithful. In Göksel A., \& Kerslake, C. (eds.), Studies on Turkish and Turkic Languages: Proceedings of the 9th International Conference on Turkish Linguistics, 12-14 August 1998, Oxford, 11-18. Wiesbaden: Harrassowitz.

Kornfilt, J. (1997). Turkish grammar. London: Routledge.

Lewis, G. (2000). Turkish grammar ( $2^{\text {nd }}$ edition). New York: Oxford University Press.

Pater, J. (2004). Austronesian nasal substitution and other NC effects. In McCarthy, J. (ed.). Optimality Theory in Phonology: A Reader. Oxford and Malden, MA: Blackwell.

Prince, A., \& Smolensky, P. (1993). Optimality Theory: Constraint interaction in generative grammar, Rutgers Center for Cognitive Science Technical Report TR-2.

Sezer, T. (2017). TS Corpus Project: An online Turkish Dictionary and TS DIY Corpus. European Journal of Language and Literature 9 (1), 18-24.

Sezer, T. (2016). Tweets Corpus: Building a Corpus by Social Media. Journal of Education and Social Sciences (210), 621-633.

Smolensky, P. (1996). The initial state and 'richness of the base' in Optimality Theory. Technical Report JHU-Cogsci-96-4. John Hopkins University.

Taneri, M. (1990). A type of reduplication in Turkish. Kansas working papers in Linguistics, 15, 96-132.

Wedel, A. (1999). Turkish emphatic reduplication (master's thesis). UC Santa Cruz. 